\title{
Gênero, corpo e beleza no discurso publicitário
}

\section{Resumo}

Buscando reconhecer as estratégias discursivas que estão sendo utilizadas em anúncios publicitários direcionados à mulher, o presente estudo se propõe a realizar uma análise semiolinguística, com o intuito de refletir sobre a publicidade persuasiva brasileira e suas marcas de gênero no Brasil. A televisão e o varejo de moda foram escolhidos como meio e segmento a serem observados, respectivamente, através dos anúncios de três empresas Marisa, Renner e Riachuelo. Pode-se perceber que atualmente, mesmo tentando romper com certos discursos tradicionais a respeito da mulher, a publicidade ainda não consegue se desvincular de estratégias discursivas clássicas e reducionistas no processo de sedução e persuasão do seu público-alvo, sobretudo em se tratando de televisão.

Palavras-chave: Discurso publicitário. Estratégias discursivas. Gênero. Corpo. Beleza.

\begin{abstract}
Seeking to recognize the discursive strategies that are being used in advertisements aimed at women, the present study proposes to perform a semiolinguistic analysis, with the intention of reflecting about Brazilian persuasive advertising and its gender marks. The choice fell on television and the fashion retail, as a means and segment to be observed. For this reason, television and fashion retail were chosen as the medium and segment to be observed, respectively, through the advertisements of three companies - Marisa, Renner and Riachuelo. It can be noticed that, even trying to break with certain traditional discourses about women, advertising still can't dissociate itself from old and traditional discursive strategies in the seduction and persuasion of this public, especially in the case of television.
\end{abstract} Keywords: Advertising discourse. Discursive strategies. Gender. Body. Beauty.

\section{Introdução}

Atualmente, a maneira de como a mulher é representada no discurso publicitário parece estar sendo criticada com mais frequência, principalmente através da internet. Essa problemática frequentemente é pauta de publicações como "Comunicação e igualdade de gênero" (HADDAD, 2015) que fala sobre a liberdade das mulheres e a igualdade de

1 Doutoranda em Comunicação e Informação (UFRGS), mestra em Comunicação Social (PUCRS).paularviegas@gmail.com 


\section{VOZES $_{\text {\&DÁLOGO }}^{\mid}$}

Itajaí, v. 17, n. 02, jul./dez. 2018

gênero, através de diversos exemplos machistas de discurso publicitário; "Chegou o briefing do dia da mulher, e agora?" (FABRIS, 2016) - que mostra meios de uma empresa participar desta data sem correr o risco de sofrer uma crise, principalmente com o argumento que este é um dia de luta e não de comemoração; e "Machismo é a regra da casa” (DIP, 2015) - que aborda a representação da mulher na publicidade como um problema que nasce com os próprios publicitários e suas organizações de trabalho.

Os consumidores parecem estar incomodados e cobram representações na publicidade menos estereotipadas e mais inclusivas. Alguns discursos publicitários já mudaram o foco, buscando repensar o modo de informar e vender seus produtos e serviços. Entretanto, diversos anúncios ainda utilizam estratégias clássicas com abordagens tradicionais que acabam reforçando determinados estereótipos de gênero que minimizam, infantilizam e violentam simbolicamente a mulher.

Aqui, a publicidade é vista como um agente do discurso da desigualdade, entre muitos outros. Dessa forma, esta investigação se preocupará, principalmente, com pequenas marcas de desigualdade de gênero nas estratégias discursivas da publicidade. Podem até parecer apenas piadas, ou frases sem importância, mas estes discursos são construídos na linguagem e pela linguagem e, por isso, não podem ser percebidos apenas como representação do cotidiano, mas também como construtores da realidade (TRINDADE, 2012). Nesse sentido, o problema de pesquisa é representado pelo seguinte questionamento: que estratégias discursivas estão sendo utilizadas na publicidade brasileira direcionadas às mulheres?

Para isso, o estudo contará com uma abordagem teórico-metodológica sobre o discurso publicitário através do método semiolinguístico de Chauraudeau, o que será articulado com os conceitos de performatividade de gênero (BUTLER, 2000; 2016); a subjetividade do corpo (SANTAELLA, 2004) e o mito da beleza (WOLF, 1992).

\section{Discurso publicitário como encenação}

De acordo com Charaudeau, todo ato de linguagem é uma encenação, e no discurso publicitário, isto fica ainda mais claro. Há uma montagem, como num teatro: há um espaço, luzes, sons, atores e texto. Os sujeitos que participam do discurso são os protagonistas desta atuação. O sujeito que recebe a mensagem cria uma série de hipóteses do que poderiam ser as intenções daquele que produz, levando a diferentes interpretações.

Compreendendo contextos e intencionalidades do discurso, o ato de linguagem não pode ser considerado neutro, apenas com efeitos pretendidos e ligados a uma situação além do próprio discurso. Assim, é possível:

[...] conceber o ato de linguagem como produzido por um emissor determinado, em um dado contexto sócio-histórico. Disso resulta a ideia de que a linguagem é um objeto não transparente. [...] $\mathrm{O}$ ato de 


\section{VOZES $_{\text {\&IÁLORO }}^{\mid}$}

Itajaí, v. 17, n. 02, jul./dez. 2018

linguagem não esgota sua significação em sua forma explícita. Este explícito significa outra coisa além de seu próprio significado, algo que é relativo ao contexto sócio-histórico (CHARAUDEAU, 2010:17, grifo do autor).

De uma maneira simplificada, pode-se observar duas instâncias no discurso midiático: (1) a instância de produção, que "compreende vários tipos de atores: os da direção do organismo de informação que cuidam da saúde econômica da empresa e de sua organização competitiva" (CHARAUDEAU, 2006:73), que no caso da publicidade podem ser compreendidos como os funcionários de uma agência de publicidade, os anunciantes, as assessorias de comunicação, os profissionais de relações públicas, etc.; e a (2) instância de recepção, que recebe a mensagem produzida. Dentro dessas instâncias são delimitados quatro protagonistas da encenação: EUe, EUc, TUd e TUi (CHARAUDEAU, 2010). Além disso, há o $\mathrm{ELE}^{\mathrm{o}}$, que se refere ao produto ou objeto de troca.

O EUe é o enunciador, que é responsável pelo efeito de discurso e está sempre presente no ato de linguagem. É uma imagem de enunciador construída pelo EUc. O enunciador existe no ato e pelo ato da produção-interpretação, apesar de não ser totalmente transparente, uma vez que é mascarado pelo EUc. O sujeito comunicante, ou EUc, é o agente que se institui como locutor e articulador. Ele é o iniciador do processo de produção, construído em função das circunstâncias de discurso. O TUd é o destinatário, ou seja, o "interlocutor fabricado pelo EU como destinatário ideal, adequado ao seu ato de comunicação” (CHARAUDEAU, 2010, p. 45). É um sujeito imaginado, um sujeito de fala, que depende do EU. Já o TUi é o interpretante, ou seja, o sujeito que age fora do ato de enunciação, apesar de intervir no ato de linguagem. É o sujeito responsável pela interpretação, apesar de apresentar certa opacidade.

De acordo com Charaudeau, o mundo midiático funciona através de um jogo de espelhos: "ele reflete o espaço social e é refletido por este” (CHARAUDEAU, 2006, p.16). Isto leva a mídia a observar o que ocorre na sociedade, mas sem a obrigação de refletir apenas o real - como é possível observar com clareza na publicidade e no cinema. Assim, o discurso midiático se apresenta sempre em estado de mudança, refletindo sobre si mesmo e sobre a sociedade.

A mídia funciona através de três lógicas - econômica, tecnológica e simbólica - que serão discutidas pela perspectiva da situação de comunicação do discurso publicitário. A lógica econômica é o fazer viver de uma empresa. Sendo a publicidade apenas existente dentro de uma sociedade capitalista, os fluxos financeiros também fazem parte da rotina, mas são frequentemente ocultados pelas demais lógicas. Enquanto isso, a lógica tecnológica compreende a difusão da mensagem. No caso deste estudo, é a mídia televisiva, que utiliza imagem e fala, sendo que tanto o visual quanto o verbal possuem uma determinada lógica, o que gera um sistema semiológico específico com universos de sentidos particulares (CHARAUDEAU, 2006). Por fim, a lógica simbólica é a que controla a construção de sentidos possíveis do discurso. Ela diz respeito ao dever democrático cidadão, 


\section{VOZES $_{\& \text { DIÁLORO }}^{\mid}$}

Itajaí, v. 17, n. 02, jul./dez. 2018

relacionando-se com o discurso de informação. Também está ligada ao impacto na opinião pública e à vida nas comunidades sociais.

Segundo Charaudeau (1983), a publicidade desloca o lugar de produto, ocultando a lógica econômica, vendendo através de sua lógica tecnológica algo muito mais simbólico e, por este motivo, a lógica simbólica comanda as demais. É através da lógica simbólica que são reforçados estereótipos que discriminam determinados grupos e desfavorecem a diversidade. Esses discursos muitas vezes utilizam abordagens tradicionais para diminuir o ruído entre a produção e a recepção, aumentando a possibilidade de que os sentidos visados sejam atingidos.

Dentro dessas regras próprias, podemos incluir a permissão da ficção na publicidade, ou um "mundo das aparências", na lógica da "prevalência do parecer sobre o ser" (TRINDADE, 2012, p. 35). Apesar de frequentemente se mostrarem como "reais", os anúncios publicitários não têm qualquer comprometimento com a realidade. Um exemplo clássico desta problemática são as "famílias margarina”. De tanto reiterar a representação da família perfeita, os anúncios de margarina colaboram na construção de um estereótipo que se naturaliza como o ideal. A "família margarina” é a família considerada social e culturalmente perfeita, normalmente branca, com um pai, uma mãe e alguns filhos, todos parecidos, sentados à mesa em total harmonia.

De acordo com Gastaldo, "paralelamente à finalidade comercial explícita, vendemse também estereótipos, ideologia, preconceitos [...] ajudando a legitimar uma dada configuração de forças no interior da sociedade" (GASTALDO, 2013, p. 25). A persuasão se dá, então, por identificação, ou por uma busca de se identificar com a realidade representada - que muitas vezes naturaliza papéis sociais restritos, reforçando estereótipos negativos à mulher.

\section{A performatividade do gênero na publicidade}

O discurso - tanto o social quanto o midiático - tem uma importante função nas desigualdades de gênero. Nos anúncios veiculados por volta dos anos 50, 60 e 70, é possível perceber diversos exemplos de reiteração de uma norma em que a mulher é a dona de casa, devota ao seu marido, por exemplo.

Segundo Marcondes (2002), no início dos anos 50 as mulheres eram o público-alvo mais frequente da publicidade. Para o autor, "é essa mulher, correta e careta no lar, que vai sustentar a grande tendência da comunicação nesse início de década. Ela, no papel coadjuvante, carente e submissa, a que venera e admira” (MARCONDES, 2002, p. 33). Estas questões são discutidas na obra "Mística Feminina", de Friedan (1971). As mulheres dos anos 60 estavam cercadas por realidades onde o papel da mulher era procurar realizarse como esposa e mãe, sem enxergar outros caminhos possíveis. Nessa época, o estereótipo de dona de casa americana era uma mulher branca, heterossexual, sadia, bonita e educada 


\section{VOZES $_{\text {\&IÁLORO }}^{\mid}$}

Itajaí, v. 17, n. 02, jul./dez. 2018

e que apenas se dedicava ao marido, aos filhos e ao lar. Encenação que ainda é muito explorada pela publicidade nos dias de hoje.

Segundo Wolf (1992), mesmo após as grandes revoluções e avanços feministas, as mulheres não se sentem plenamente livres e nem sempre se sentem à vontade para admitir suas inseguranças com a aparência física, corpo, rosto e comportamento de um modo em geral. Segundo a autora, "à medida que as mulheres se liberaram da mística feminina da domesticidade, o mito da beleza invadiu esse terreno perdido" (WOLF, 1992, p. 12). Com um discurso objetivo e não neutro, a publicidade se apresenta como um agente midiático que possibilita o reforço repetitivo de ideias e modelos de comportamento, como já foi discutido anteriormente. Ao mostrar imagens de mulheres a partir de uma ideia de beleza homogênea - branca, jovem, magra - esse tipo discurso colabora com o mito da beleza e suas consequências na sociedade.

Wolf aponta que o mito não tem nada a ver com as mulheres, pois "o mito da beleza, na realidade, sempre determina o comportamento e não a aparência” (WOLF, 1992, p. 17). Um exemplo deste "deslocamento" do problema central é o envelhecimento da mulher: de acordo com a autora, ele diz muito mais a respeito de um medo acerca do poder que as mulheres adquirem, com o tempo, do que uma aversão a rugas. A autora aponta que "a cultura estereotipa as mulheres para que se ajustem ao mito, nivelando o que é feminino em beleza-sem-inteligência ou inteligência-sem-beleza” (WOLF, 1992, p. 77). Isso ocorre quando a mídia cria uma "imagem ideal” de mulher, que deve ser buscada constantemente.

Santaella (2004) mostra como há uma subjetivação e complexidade no corpo, muito embora ele seja entendido como algo pouco refletido no senso comum, com fronteiras definidas e encerrado em si mesmo.

Olhamos para nós mesmos no espelho e para os outros e vemos entidades com fronteiras definidas a que chamamos de corpos. [...] Muito mais do que percebemos e experienciamos é construído socialmente: nossa identidade psíquica e sexual, o que constitui o prazer e a dor, onde estão as fronteiras do eu (SANTAELLA, 2004, p. 9).

A autora mostra como diferentes autores trabalham a "ideia do eu", ultrapassando as noções de indivíduo, sujeito e subjetividade. Para ela, "o sujeito, mesmo na sua forma mais íntima, é um processo de semiose” (SANTAELLA, 2004, p. 124) e suas imagens são descentradas e instáveis. Aqui se constrói uma "ideia do eu", onde o corpo se mostra de forma unificada, regulando as práticas sociais dos indivíduos. Segundo Santaella, o imaginário se alimenta das imagens que a mídia reproduz, incessantemente que mostram um "corpo reificado, fetichizado, modelizado como ideal a ser atingido em consonância com o cumprimento da promessa de uma felicidade sem máculas" (SANTAELLA, 2004, p. 125). Esse corpo se constitui regulando as práticas de gênero, desenvolvidas através do mito da beleza e outras articulações sociais. 


\section{VOZES $_{\text {\&IÁLORO }}^{\mid}$}

Itajaí, v. 17, n. 02, jul./dez. 2018

De acordo com Butler (2016), é preciso pensar muito além das categorias "homem" e "mulher", visto que são noções instáveis. Segundo Butler, o reforço das categorias de identidade "engendram, naturalizam e imobilizam" (BUTLER, 2016, p. 24). Assim como Nicholson (2000), Butler acredita que a diferenciação sexual pareceu importante para o feminismo, mas é preciso ir além. De acordo com a autora, a diferença sexual é simultaneamente material e discursiva, funcionando como um ideal regulatório, cuja materialização é imposta através da reiteração forçada destas normas. Deste modo, não se pode universalizar a experiência das mulheres, como se o sujeito denominado "mulheres" fosse presumido e estável.

De acordo com o que Butler denomina de "sistema de gênero binário oposicional" (BUTLER, 2016, p. 52), homens e mulheres são vistos como opostos e/ou complementares em um âmbito linguageiro da heterossexualidade presumida. Deste modo, "a instituição de uma heterossexualidade compulsória e naturalizada exige e regula o gênero como uma relação binária, em que o termo masculino diferencia-se do termo feminino, realizando-se essa diferenciação por meio das práticas do desejo heterossexual" (BUTLER, 2016, p. 53). Essa estrutura binária é apresentada como uma coerência interna. Mas necessita de uma reiteração e naturalização da heterossexualidade compulsória, funcionando como um aparelho de produção excludente.

Neste sentido, a autora sugere pensar o gênero como performático, pois ele está não apenas no discurso, mas também na materialidade do corpo, através de atos, gestos e ações que são performativos. Assim, os gêneros não serão verdadeiros nem falsos, mas apenas efeitos da verdade. A performatividade necessita de repetições em ações públicas, sendo que normalmente ela não é entendida como performática em si, mas como algo natural. $\mathrm{O}$ efeito do gênero deve ser produzido incessantemente através de gestos, movimentos e estilos corporais, constituindo uma ilusão de permanência deste eu (BUTLER, 2016). Na mídia, é possível observar diversos exemplos da heterossexualidade compulsória, atuando de acordo com um binarismo hierárquico, o que pode ser reconhecido nos anúncios aqui analisados.

\section{Análise semiolinguística}

Para responder o problema de pesquisa, que busca identificar as estratégias discursivas utilizadas em anúncios publicitário direcionados às mulheres, foi realizada seleção do corpus de análise a partir da coleta de anúncios publicitários na Rede Globo nos intervalos comerciais da semana que antecedeu o Dia Internacional das Mulheres em 2016. Dentre os anúncios coletados, um segmento que se destacou foi o das lojas de varejo de moda - representado pelos anúncios das marcas Marisa, Renner e Riachuelo. 


\section{VOZES}

Itajaí, v. 17, n. 02, jul./dez. 2018

O primeiro anúncio a ser analisado é o da marca "Marisa", uma empresa com foco na classe $\mathrm{C}$ que se tornou referência na venda para a "nova classe média" brasileira. $\mathrm{O}$ anúncio selecionado para o corpus explora a amizade entre as mulheres através de uma conversa descontraída. A encenação se passa em quarto, onde quatro mulheres experimentam lingeries e conversam sobre isso.

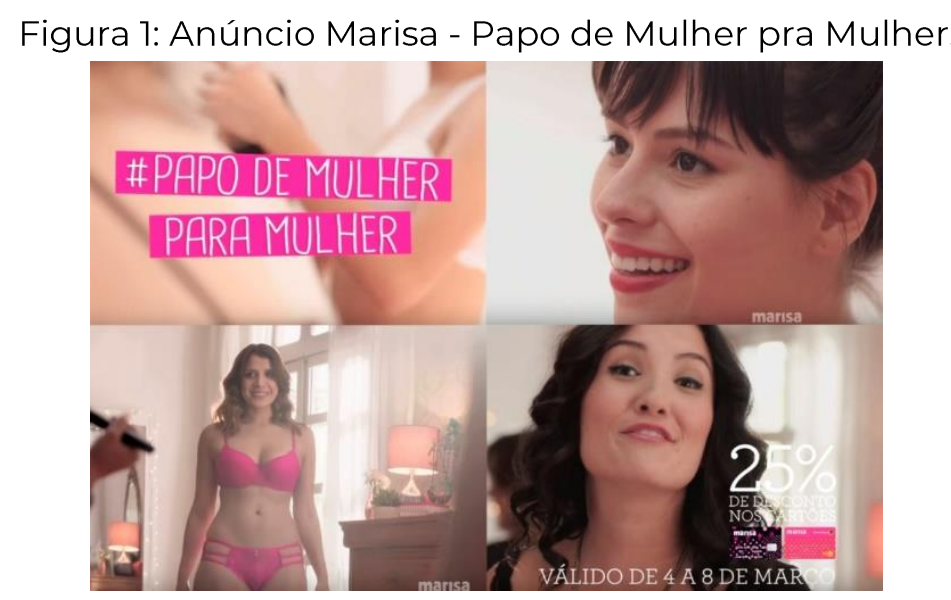

Fonte: Montagem desenvolvida pela autora².

O segundo anúncio analisado é das Lojas Renner, que é atualmente a varejista de moda que mais fatura no Brasil. Através do slogan "você tem seu estilo, a Renner tem todos", a empresa deseja se posicionar como uma marca que respeita a diversidade de ser e de viver de cada um. O anúncio constituinte do corpus da presente pesquisa mostra uma encenação de modo a apresentar a coleção outono/inverno 2016 das Lojas Renner. A encenação se dá através de duas atrizes e um ator, e tem como palco uma cafeteria. As duas personagens, que parecem trabalhar lá, conversam sobre um homem que aparece no final da cena. 


\section{VOZES $_{\text {\&IÁLORO }}^{\mid}$}

Itajaí, v. 17, n. 02, jul./dez. 2018

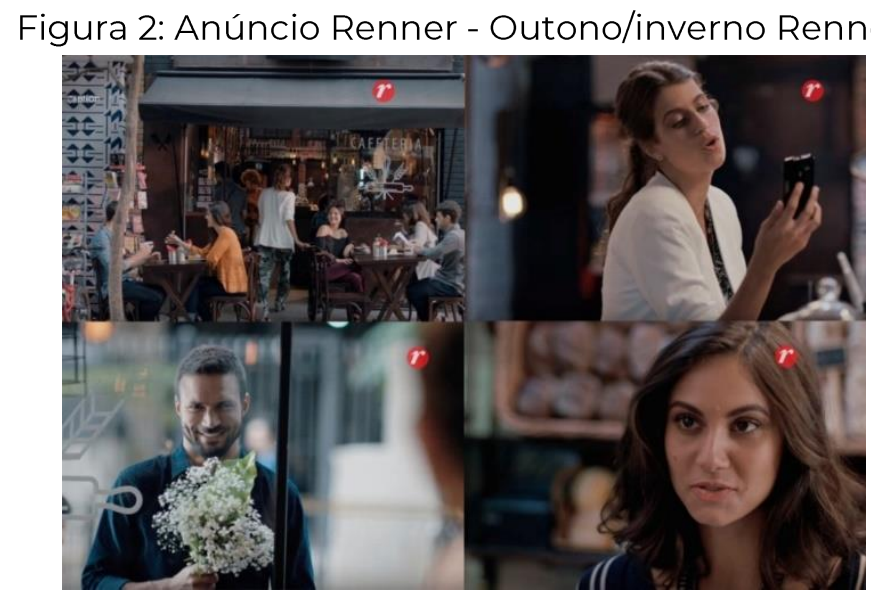

Fonte: Montagem desenvolvida pela autora³.

O terceiro e último anúncio a ser analisado é da Riachuelo, uma loja de departamento brasileira que se posiciona como sendo a maior empresa neste segmento. $\mathrm{O}$ anúncio "Dupla Fashion”, que apresenta a Nova Coleção Riachuelo de 2016, explora uma constante do meio da moda: o uso de modelos/manequins para apresentar seus produtos.

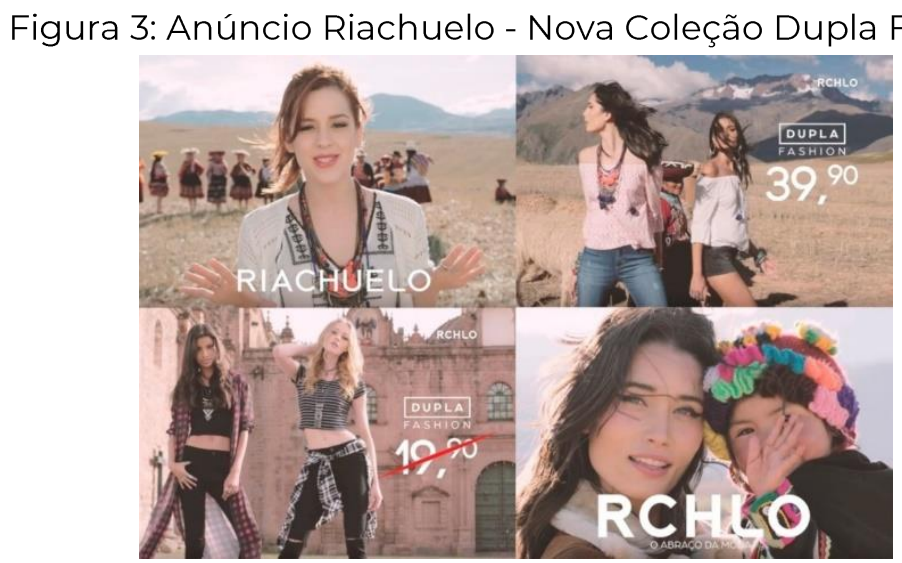

Fonte: Montagem elaborada pela autora ${ }^{4}$.

Cada um dos três anúncios coletados foi observado e descrito de forma empíricodedutiva através dos três níveis de análise, que são: (1) situacional: composto pela situação de comunicação, o contexto inscrito no interior do ato de linguagem e o espaço externo de restrições do discurso, onde devem ser respondidas as perguntas "estamos aqui para dizer ou fazer o quê?", “quem fala a quem?" e "sobre o quê?”; (2) comunicacional: onde são identificados os sujeitos discursivos (TU e EU), além de discutir as maneiras de falar e os papéis linguageiros, o que acontece no momento de responder a pergunta "estamos aqui para falar de que modo?”; e (3) discursivo: onde se observa a intervenção do sujeito falante

3 Com base no vídeo publicado no Youtube, disponível em:

<https://www.youtube.com/watch?v=8CdOHP5mRLU>. Acesso em: 9 maio 2016.

4 Com base no vídeo publicado no Youtube, disponível em:

<https://wnw.youtube.com/watch?v=U-OZOzSu9lo>. Acesso em: 9 maio 2016. 


\section{VOZES $_{\text {\&IÁLORO }}^{\mid}$}

Itajaí, v. 17, n. 02, jul./dez. 2018

enquanto enunciador em suas condições de legitimidade, credibilidade e captação, o deslocamento de lugar (CHARAUDEAU, 2005). Este esquema pode ser observado na tabela a seguir.

Tabela 1: Três níveis da análise semiolinguística.

\begin{tabular}{|c|c|c|c|}
\hline Níveis/Marcas & Marisa & Renner & Riachuelo \\
\hline Situacional & $\begin{array}{l}\text { O contexto inscrito } \\
\text { no interior do ato de } \\
\text { linguagem se passa } \\
\text { em um ambiente } \\
\text { privado, partilhado } \\
\text { apenas pelas atrizes } \\
\text { da cena. É uma } \\
\text { situação informal e } \\
\text { íntima, que busca } \\
\text { aproximar marca e } \\
\text { consumidor. Esta é } \\
\text { uma situação onde } \\
\text { amigas se } \\
\text { encontram e vivem } \\
\text { momentos em torno } \\
\text { de um propósito, } \\
\text { que aqui é a lingerie. } \\
\text { A finalidade deste } \\
\text { discurso parece se } \\
\text { encontrar na na na } \\
\text { liberaça de de } \\
\text { inseguranças ditas } \\
\text { femininas. }\end{array}$ & $\begin{array}{l}\text { A insegurança da mulher } \\
\text { é explorada, assim como } \\
\text { no anúncio anterior. } \\
\text { Possivelmente, antes do } \\
\text { ato de encenação que } \\
\text { aparece no anúncio } \\
\text { publicitário, a Atriz } 1 \text { e o } \\
\text { Ator da cena estão no } \\
\text { início de um } \\
\text { relacionamento. Pelo } \\
\text { beijo, ao final do } \\
\text { referido anúncio, os dois } \\
\text { já haviam se envolvido } \\
\text { amorosamente. Ela } \\
\text { parece estar ansiosa, } \\
\text { esperando alguma } \\
\text { interação vinda do rapaz, } \\
\text { uma referência a a } \\
\text { romances clássicos, mas } \\
\text { baseado em interações } \\
\text { no ambiente virtual. }\end{array}$ & $\begin{array}{l}\text { O anúncio não } \\
\text { apresenta uma } \\
\text { história ou narrativa, } \\
\text { como os demais, pois } \\
\text { dá mais destaque aos } \\
\text { produtos } \\
\text { anunciados. Este é } \\
\text { um tipo de anúncio } \\
\text { comum, mas se } \\
\text { diferencia ao trazer } \\
\text { elementos novos: o } \\
\text { ambiente em que se } \\
\text { passa (Cusco-Peru), } \\
\text { os pontos turísticos, } \\
\text { as lhamas, além das } \\
\text { mulheres e meninas } \\
\text { com roupas típicas } \\
\text { do local. Não há uma } \\
\text { contextualização do } \\
\text { porquê da temática. }\end{array}$ \\
\hline $\begin{array}{l}\text { Comunicacio- } \\
\text { nal }\end{array}$ & $\begin{array}{l}\text { No anúncio, o EUe } \\
\text { é a marca "Marisa", } \\
\text { que é a empresa } \\
\text { anunciante, além da } \\
\text { agência Giacometti } \\
\text { Comunicação que } \\
\text { criou o anúncio. } \\
\text { Porém, o destaque } \\
\text { maior é para o EUc. } \\
\text { Este sujeito é } \\
\text { representado pelas } \\
\text { atrizes presentes na } \\
\text { cena, que são as } \\
\text { quatro amigas. O } \\
\text { TUd é o sujeito } \\
\text { imaginado, que aqui } \\
\text { parece ser } \\
\text { principalmente a } \\
\text { mulheres da classe } \\
\text { C, embora o }\end{array}$ & $\begin{array}{l}\text { EUe são as Lojas Renner } \\
\text { e a agência Paim, } \\
\text { responsável pela criação } \\
\text { deste anúncio. O EUc é } \\
\text { representado pelos } \\
\text { atores da cena e pela } \\
\text { locutora do anúncio que } \\
\text { fala diretamente com a } \\
\text { instância de recepção, no } \\
\text { final do anúncio: “As } \\
\text { mulheres adoram uma } \\
\text { novidade, mesmo que já } \\
\text { seja um clássico”. O } \\
\text { TUd são mulheres de } 18 \\
\text { a } 39 \text { anos, na faixa de } \\
\text { consumo média e } \\
\text { média-alta. O TUi são as } \\
\text { mulheres que realmente } \\
\text { foram atingidas pelo } \\
\text { anúncio de alguma }\end{array}$ & $\begin{array}{l}\text { O EUe é formado } \\
\text { pela Riachuelo e pela } \\
\text { agência BigMan. O } \\
\text { EUc parece estar } \\
\text { representado } \\
\text { explicitamente por } \\
\text { Sophia Abrahão. A } \\
\text { fala da locutora soa } \\
\text { informal } \\
\text { descontraída, apesar } \\
\text { de ser um texto } \\
\text { escrito de forma } \\
\text { objetiva. O TUd - ou } \\
\text { público-alvo - da } \\
\text { marca são mulheres } \\
\text { da classe C, sem } \\
\text { idade específica. } \\
\text { Apesar disso, nem } \\
\text { todas as mulheres } \\
\text { brasileiras parecem }\end{array}$ \\
\hline
\end{tabular}




\section{VOZES $_{\text {\&IÁLORO }}^{\mid}$}

Itajaí, v. 17, n. 02, jul./dez. 2018

\begin{tabular}{|c|c|c|c|}
\hline & $\begin{array}{l}\text { anúncio vá mais } \\
\text { longe através dos } \\
\text { saberes } \\
\text { compartilhados As } \\
\text { maneiras de falar } \\
\text { parecem ser as mais } \\
\text { informais possíveis. } \\
\text { A proposição } \\
\text { parece querer } \\
\text { legitimar a marca } \\
\text { como portadora de } \\
\text { um entendimento } \\
\text { sobre lingerie. }\end{array}$ & $\begin{array}{l}\text { forma, que dependem } \\
\text { das circunstâncias do } \\
\text { discurso, mas que agem } \\
\text { independentemente do } \\
\text { EU. Apesar de se passar } \\
\text { em um ambiente } \\
\text { informal, o que se } \\
\text { conecta com a } \\
\text { "novidade, as posturas e } \\
\text { atitudes são elegantes - } \\
\text { ligando-se mais ao } \\
\text { "clássico". }\end{array}$ & $\begin{array}{l}\text { estar representadas } \\
\text { neste padrão da } \\
\text { manequim de moda, } \\
\text { pois apresentam uma } \\
\text { diversidade de } \\
\text { tamanhos e cores em } \\
\text { seus corpos. Assim, } \\
\text { nem todas as } \\
\text { mulheres vão se } \\
\text { enxergar naquela } \\
\text { cena, mas podem } \\
\text { sentir uma sensação } \\
\text { de querer/dever ser. }\end{array}$ \\
\hline Discursivo & $\begin{array}{l}\text { Nesta condição, } \\
\text { circulam os saberes } \\
\text { compartilhados } \\
\text { entre o EU e o TU } \\
\text { sobre a temática do } \\
\text { anúncio, onde EU } \\
\text { se mostra um } \\
\text { portador legítimo da } \\
\text { mensagem. } \\
\text { Marisa parece ser } \\
\text { uma marca que tem } \\
\text { legitimidade sobre o } \\
\text { assunto, o que } \\
\text { também influencia } \\
\text { na credibilidade. } \\
\text { Aqui, há } \\
\text { deslocamento de } \\
\text { lugar do produto } \\
\text { onde o "objeto de } \\
\text { troca" (lingerie) é } \\
\text { substituído pelo } \\
\text { "objeto ideal". } \\
\text { Neste sentido, o } \\
\text { objeto ideal a ser } \\
\text { buscado parece ser } \\
\text { o "uau" - um elogio } \\
\text { - que trará } \\
\text { segurança para este } \\
\text { TU. O meio para } \\
\text { atingir isso, } \\
\text { implicitamente, é a } \\
\text { lingerie vendida nas } \\
\text { lojas Marisa. }\end{array}$ & $\begin{array}{l}\text { Por estar há muito } \\
\text { tempo no mercado, } \\
\text { oferecendo produtos de } \\
\text { todos os estilos, a marca } \\
\text { se posiciona como uma } \\
\text { instância legítima. A } \\
\text { condição de captação } \\
\text { está adequada a um } \\
\text { público mais tradicional, } \\
\text { através do romance. Esta } \\
\text { questão se alinha ao que } \\
\text { Butler (2016) denomina } \\
\text { como } \\
\text { "heterossexualidade } \\
\text { presumida”. Encenações } \\
\text { como esta apresentam } \\
\text { uma performatividade } \\
\text { de gênero clara, porém } \\
\text { não transparente ao se } \\
\text { ocultar através de um } \\
\text { discurso publicitário } \\
\text { casual. O "objeto de } \\
\text { troca”, ou seja, os } \\
\text { vestuários vendidos } \\
\text { pelas Lojas Renner são } \\
\text { ocultados por um } \\
\text { "objeto ideal” - que aqui } \\
\text { parece ser esta mulher } \\
\text { bonita, jovem e sóbria } \\
\text { que aguarda e recebe } \\
\text { uma resposta romântica } \\
\text { de um homem. }\end{array}$ & $\begin{array}{l}\text { O produto é } \\
\text { apresentado pela } \\
\text { figura das modelos, } \\
\text { que parecem ser o } \\
\text { "objeto ideal”. O que } \\
\text { se vende, através } \\
\text { deste objeto ideal, é a } \\
\text { mulher magra, alta, } \\
\text { branca, jovem, } \\
\text { bonita e confiante. } \\
\text { Uma mulher } \\
\text { tipicamente modelo, } \\
\text { que é elegante e } \\
\text { segura com sua } \\
\text { aparência. A imagem } \\
\text { de Sophia Abrahão } \\
\text { não ganha tanto } \\
\text { destaque, nem a das } \\
\text { habitantes do local - } \\
\text { que usam trajes } \\
\text { típicos do povo } \\
\text { quéchua. } \\
\text { destaque, realmente, } \\
\text { é das manequins. As } \\
\text { mulheres locais } \\
\text { ficam em segundo } \\
\text { plano, sem usar o } \\
\text { vestuário anunciado. } \\
\text { E também não se } \\
\text { misturam com as } \\
\text { modelos, a não ser a } \\
\text { criança no colo de } \\
\text { uma delas no final do } \\
\text { anúncio. }\end{array}$ \\
\hline
\end{tabular}

Fonte: Desenvolvida pela autora. 


\section{VOZES $_{\text {\&IÁLORO }}^{\mid}$}

Itajaí, v. 17, n. 02, jul./dez. 2018

Nos anúncios analisados, é possível observar diversos pontos em comum entre seus discursos. São estas constantes - unidas a outros anúncios publicitários e demais produtos midiáticos, além dos discursos sociais - que reforçam modelos ideais de beleza e comportamentos direcionados à mulher. Uma grande semelhança entre todos os anúncios, e que se repete com exaustão na mídia em geral, é o uso de atrizes brancas, jovens, magras e quase sem imperfeições. Exceção feita a uma amiga parda/negra no primeiro anúncio, e às mulheres quéchua, a diversidade étnica e racial dos anúncios analisados é quase nula. Na rapidez do anúncio publicitário, o uso de estereótipos é comum, haja vista a necessidade da economia na percepção da realidade (TRINDADE, 2012). Essa reiteração cria certos padrões e reforça esse objeto ideal a ser seguido.

A subjetividade do corpo não possui muito espaço em um anúncio publicitário de 30 segundos. A mensagem deve ser compreendida e absorvida rapidamente. Nesta velocidade de raciocínio, as fronteiras do eu (SANTAELLA, 2004) e já limitadas, parecem se tornar ainda mais apertadas. É reiterado o estereótipo da mulher delicada, romântica, comportada e preocupada com o corpo. Apesar dos esforços do anúncio da Marisa, ao mostrar que toda mulher pode usar lingerie e ser "uau" através da fala "se tem corpo, usa", a imagem da atriz não sai muito do padrão de beleza atual.

Aqui se pode perceber como se articula o mito da beleza, que segundo Wolf (1992) regula comportamento e não aparência. É um mito muito ligado a (in)segurança da mulher em relação ao próprio corpo e a Marisa se apropria desta questão para apresentar seu produto. Entretanto, a marca o faz com uma atriz que não está tão fora de um "padrão" de beleza e magreza. Apesar de não ter um corpo de modelo, a atriz - que parece insegura ao vestir a lingerie rosa (Figura 1) - ainda está dentro de um padrão de beleza recorrente nos anúncios publicitários. Por este motivo, apesar de querer libertar as mulheres de uma insegurança, pode causar o efeito contrário: ao escolher uma atriz branca e jovem que possui um corpo sem flacidez ou irregularidades, o anúncio corre o risco de não atender aos efeitos possíveis pretendidos pelo EU. A partir de uma perspectiva implícita e inconsciente, o público-alvo (TUd), imaginado pelo EU, pode não se sentir representado no discurso e não se identificar com aquela situação.

As performatividade do gênero nos anúncios analisados são potentes e bem sucedidas pois colaboram na naturalização de um sistema binário oposicional, tornando-o invisível. Estas performatividades são incorporadas de modo a se apresentarem como uma verdade absoluta, que não precisa ser questionada. A heterossexualidade e o binarismo oposicionais são, normalmente, dados como verdade, como se possuíssem uma coerência interna. Mas é na observação destes anúncios que se percebem marcas sexuadas de gênero constantes, as quais atuam como formas de reiteração e naturalização desta norma.

O anúncio da Renner fortalece a heterossexualidade e a hierarquia de gênero através de papéis bem definidos: a mulher espera e anseia por seu amado, mas não parece ir atrás deste desejo. Finalmente, o homem aparece, trazendo consigo um sorriso, um 


\section{VOZES $_{\text {\&IÁLORO }}^{\mid}$}

Itajaí, v. 17, n. 02, jul./dez. 2018

buquê de flores e uma clássica elegância. Este romance é um problema ao traçar uma matriz excludente aos sujeitos abjetos que não se alinham a este sistema de gênero binário oposicional (BUTLER, 2016). Não é apenas um anúncio isolado que produz este efeito, mas uma larga repetição deste tipo de discurso que universaliza a experiência das mulheres reforçando determinados papéis sociais.

O ideal de beleza, difundido pela publicidade através de suas representações sociais, pode ser pensando através do duplo esquema cognitivo de Charaudeau, onde a mulher deve ter uma carência (a falta de beleza) e ir sempre em busca disso. A mulher não pode não querer ser bonita - e consequentemente magra e jovem. Pelo contrário, ela deve estar sempre atrás deste objetivo. $\mathrm{O}$ meio de atingir isto é através do produto anunciado, sejam as roupas, sejam os produtos de beleza e de rejuvenescimento, as academias, os salões de beleza, entre outros espaços e ofertas. O papel da publicidade aqui, além de expor esse “objeto ideal”, é o de mostrar meios de como atingir este objetivo, apresentando produtos que podem moldar e controlar totalmente o corpo feminino.

O anúncio da Riachuelo utiliza deste "ideal de beleza" ao usar mulheres com um padrão bem específico, que são as modelos fotográficas ou de passarela. Como o próprio nome diz, são modelos, ou seja, algo a ser copiado. O discurso publicitário, que anuncia roupas, explora esta construção visual por remeter a uma linguagem própria da moda. Essa modelo normalmente é magra e bonita, porém pálida, uma vez que as roupas expostas precisam aparecer, sobressair, fazendo com que os olhares voltem-se para o produto.

O corpo de modelo é uma aspiração muito comum nos tempos atuais, pois está construído sobre algo belo, clássico e desejável. Há uma "perfeição” naquele modelo de mulher. Perfeição que transborda através do corpo, do cabelo, do rosto. O que fica escondido é o sacrifício, a vida dura de uma modelo para se encaixar nesses padrões além das doenças - nem tão raras - como a anorexia, a bulimia e a depressão. Algumas pessoas criticam a magreza excessiva, mas isso não minimiza o problema, uma vez que os olhares ainda se voltam para o corpo da mulher.

\section{Considerações finais}

Por que o mito da beleza ainda perdura? Porque a desigualdade de gênero ainda é reforçada na publicidade? Por que a mulher ainda é direcionada a um ideal de beleza e comportamento? O que podemos perceber, com este estudo, é que a economia e a mídia ganham com a insegurança da mulher. $\mathrm{E}$ o faz, principalmente, ocultando as lógicas econômicas. É através das estratégias discursivas da publicidade que estas lógicas econômicas são ocultadas, que os anunciantes são mascarados pelas personagens da encenação e que o produto é deslocado de seu lugar de destaque. O que se vende não é a lingerie da Marisa, ou a coleção outono/inverno da Renner, ou a nova coleção 2016 da Riachuelo. O que se vende é um modelo a ser seguido, um ideal de mulher a ser desejado. 


\section{VOZES $_{\text {\&IÁLORO }}^{\mid}$}

Itajaí, v. 17, n. 02, jul./dez. 2018

A encenação, no discurso publicitário, torna pública a performatividade do gênero de modo disfarçado e pouco aparente. Uma encenação composta por diversas escolhas como atores, atrizes, as falas, o ambiente - que são pensadas na criação publicitária e que passam, geralmente, por diversos outros profissionais. É exigida uma coerência entre as mulheres, principalmente no discurso midiático, onde a prática e o desejo são apresentados como naturais, apesar de precisarem ser reforçados compulsivamente.

A instância publicitária não atua sozinha e seu discurso não está em um vácuo. Ele se relaciona através de um jogo de espelhos com a sociedade, não apenas em uma dupla direção - mídia e sociedade - mas através de múltiplos atravessamentos. A manipulação não ocorre por intermédio de uma relação de causa e efeito, mas através de estratégias de incitação, sedução e captação. A diversidade da aparência e do comportamento da mulher brasileira é substituída por um corpo branco, alto e magro, um ideal apresentado como homogêneo e coerente. Estas questões parecem ter ficado em aberto e apontam para possíveis novos estudos a serem desenvolvidos na área.

A publicidade da TV se apropria do já naturalizado mito da beleza como se fosse um saber compartilhado e legitimado por todas as mulheres, o que reforça ainda mais este discurso. Por mais que queiram romper barreiras, as empresas não podem temer perder sua tradicional clientela, um público específico da televisão, através de um novo discurso. Estes anúncios não são sempre aceitos pelo público. Atualmente, é possível observar diversas polêmicas que emergem questionamentos sobre os estereótipos femininos apresentados pela publicidade.

Para quebrar este processo sócio-histórico é necessário se inscrever neste processo. É preciso, no mínimo, reconhecê-lo como real para poder questioná-lo e mudá-lo. Esta problemática deve ser apresentada como uma discussão social inteligível, transformando algo ofuscado pelo senso comum em um problema a ser resolvido. Wolf (1992) aponta que a mudança deve vir por parte da mulher, que deve começar a recusar o mito da beleza no seu cotidiano. A aceitação de si é uma arma política potente. Mas será o suficiente? A mídia deve esperar as mudanças ocorrerem para começar a refletir um discurso mais igualitário e justo?

O que se buscou, aqui, foi trazer questionamentos sobre a mulher na publicidade e dentro do discurso acadêmico, com o intuito de discutir esta problemática entre pesquisadores e educadores da comunicação social. A educação ainda é uma potente arma política e através dela é possível realizar mudanças na realidade social, em busca da igualdade e da tolerância ao diferente. É preciso repensar o discurso publicitário, mas não apenas ele. $\mathrm{O}$ discurso em sala de aula, nos cursos de comunicação, também deve discutir a potência do discurso midiático. E a mudança deve se inscrever dentro destes saberes compartilhados. 


\section{VOZES

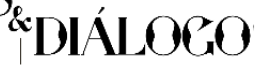

Itajaí, v. 17, n. 02, jul./dez. 2018

\section{Referências}

BUTLER, J. Corpos que pesam: sobre os limites discursivos do "sexo". In LOPES, Guacira (org.). O corpo educado: pedagogias da sexualidade. Belo Horizonte: Autêntica, 2000. p. 151-172.

Problemas de gênero: feminismo e subversão da identidade. Rio de Janeiro: Civilização Brasileira, 2016.

CHARAUDEAU, P. À propos du genre publicitaire. In: CHARAUDEAU, Patrick. Language et discours. Paris: Hachette Université, 1983.

Discurso das mídias. São Paulo: Contexto, 2006.

Linguagem e discurso: modos de organização. São Paulo: Contexto, 2010. . Uma análise semiolinguística do texto e do discurso. In: PAULIUKONIS,

M. A. L. e GAVAZZI, S. (orgs.). Da língua ao discurso: Reflexões para o ensino. Rio de Janeiro: Lucerna, 2005. p. 11-29.

DIP, A. Machismo é a regra da casa. [2015]. Disponível em http://apublica.org/2015/03/machismo-e-a-regra-da-casa/. Acesso em 27/05/2015.

FABRIS, T. Chegou o briefing de Dia da Mulher, e agora? [2016] Disponível em http://www.b9.com.br/63357/advertising/chegou-o-briefing-de-dia-da-mulher-e-agora/.

Acesso em 14/04/2016.

FRIEDAN, B. Mística feminina. Petrópolis: Vozes Limitada, 1971.

GASTALDO, É. Publicidade e sociedade: uma perspectiva antropológica. Porto Alegre: Sulina, 2013.

HADDAD, A. Comunicação e igualdade de gênero: além da estratégia publicitária. [2015?]. Disponível em http://pontoeletronico.me/2016/genero-na-comunicacao/. Acesso em 14/04/2016.

MARCONDES, P. Uma história da propaganda brasileira. Rio de Janeiro: Ediouro, 2002.

SANTAELLA, L. Corpo e comunicação: sintomas da cultura. São Paulo: Paulus, 2004 .

TRINDADE, E. Propaganda, identidade e discurso: brasilidades midiáticas. Porto Alegre: Sulina, 2012.

WOLF, N. O mito da beleza: como as imagens de beleza são usadas contra as mulheres. Rio de Janeiro: Rocco, 1992. 